\title{
Beginning Readers in Arabic and the Distance between Literary and Spoken Arabic
}

\author{
Raphiq Ibrahim \\ The Edmond J. Safra Brain Research Center for the Study of Learning Disabilities, \\ Learning Disabilities Department, University of Haifa, Haifa, Israel \\ Email: raphiq@psy.haifa.ac.il
}

Received December $22^{\text {nd }}, 2012$; revised January $24^{\text {th }}, 2013$; accepted February $8^{\text {th }}, 2013$

\begin{abstract}
Copyright (C) 2013 Raphiq Ibrahim. This is an open access article distributed under the Creative Commons Attribution License, which permits unrestricted use, distribution, and reproduction in any medium, provided the original work is properly cited.
\end{abstract}

\begin{abstract}
Two groups of kindergarten children received a battery of phonological awareness, reading, and general abilities tests across a two-year period. One of the groups received phonological training whereas the other (control) group did not. Results indicated that children who received intervention improved in certain phonological awareness skills tested at the end of kindergarten but not in reading skills tested at the end of $1^{\text {st }}$ year. These findings are in contrast to findings compared to those found by Carlisle (1995) and Lyster (2002) in English, but were in line with the findings found by Ibrahim et al. (2007) in Arabic and support the notion that normal Arab child encounters special difficulties in reading acquisition. The psycholinguistic basis and implications of these findings are discussed.
\end{abstract}

Keywords: Reading; Orthography; Phonological Awareness; Kindergarten; Arabic

\section{Introduction}

A number of studies were conducted in the last two decades in an attempt to examine the relationship between the Arabic orthographic system and cognitive processes that might be involved during word recognition. In particular, these focused on the specific characteristics of Arabic orthography and the ways these characteristics may influence the acquisition of reading (e.g. Ibrahim \& Aharon-Peretz, 2005; Feitelson, Goldstein, Iraqi, \& Share, 1993; Ibrahim, Eviatar, \& Aharon-Peretz, 2002; Eviatar, Ibrahim, \& Ganayim, 2004; Ibrahim \& Eviatar, 2009). This study was undertaken to examine the effect of intervention programs for improving the phonological awareness in kindergarten children on their first grade reading abilities in Arabic as first language. It is widely known that there is a strong link between reading development and linguistic awareness, the ability to reflect on spoken language, and that the measures for phonological awareness taken prior to reading instruction predict later reading ability (Lyster, 2002). There is good support for a strong correlation between phonological awareness and reading development (Blachman, Ball, Black, \& Tangel, 1994; Brennan \& Ireson, 1997; Bradley \& Bryant, 1983; Byrne, Freebody, \& Gates, 1992; Bowey \& Francis, 1991; Durgunoglu \& Oney, 1999; Ehri \& Wilce, 1980; Mann, 1998; Mann \& Liberman, 1984; Metsala, 1999; Olfsson \& Lundberg, 1983; Stanovich, 1986; Wagner \& Torgesen, 1987). In the case of Arabic the findings were controversial (Ibrahim, Eviatar, \& AharonPeretz, 2007). In our previous research (see, Eviatar \& Ibrahim, 2001), we asked how early exposure to two languages affects the cognitive system?

In our recent study (Ibrahim, Eviatar, \& Aharon-Peretz, 2007), we tried to explore how the advantages in phonological awareness revealed by the Russian-Hebrew bilinguals and the Arab children are related to reading performance in first grade the possibility that bilingualism, which has been shown to affect metalinguistic abilities, influences reading performance via these abilities. The consensus in the field is that learning a second language permits children to view their language as one system among others, and thereby enhances their reading ability. It is believed that the systematic separation of form and meaning that is experienced in an early bilingualism gives children added control of language processing. Focus on reading performance and the variables that influence it have revealed strong correlative relations with metalinguistic skills. The majority of previous investigations of the relationship between bilingualism and reading ability were conducted in English and other Indu-Europian languages. The general pattern of the effects of bilingualism is the following: bilinguals achieve higher scores than monolinguals on tests of arbitrariness (Edwards \& Christofersen, 1988) and phonological awareness (Dash \& Mishra, 1992), and lower scores than monolinguals on tests of vocabulary size (Doyle, Champagne, \& Segalwitz, 1978). Concerning phonological awareness many studies have demonstrated that children's performance in various phonological awareness tasks are strongly related to the acquisition of reading skills in English (Bradly \& Bryant, 1985), Italian (Cossu, Shankweiler, Liberman, Katz, \& Tola, 1988), French (Bertlson, Morais, Alegria, \& Content, 1985), Spanish (deManrique \& Gramigna, 1984). These researches hypothesized that the ability to reflect on phonemes presupposes the ability to reflect on words, but not vice verse. A closer look at our results revealed that exposure to second language in early childhood affect reading skill among children in the first grade. In that regard this finding converges with other's reports showed that bilingualism is powerful predictor of the speed and effieciency of reading acquisition (Da Fontoura \& Siegel, 1995). However, 
the above correlative studies tell us very little about the nature of this relationship. This longitudinal study was undertaken to examine the effect of intervention programs for improving the phonological awareness in kindergarten children on their first grade reading abilities in Arabic as first language.

\section{Reading and Linguistic Skills}

Reading is a process of decoding (deciphering words) and understanding written language. This process commences with visual stimulation and concludes with an understanding of the idea which the writer wished to convey (Rayner \& Pollatsek, 1989). Beyond this, reading is a linguistic skill, difficulties in which can derive from problems in language processing (Mann, 1998). There is much research indicating that specific linguistic and cognitive processes are required, in addition to the integration of these processes, for reading development. It is possible to divide the processes necessary for reading acquisition into two dimensions: word recognition and auxiliary cognitive processes (Shany, Zeiger, \& Ravid, 2001). The first dimension comprises the processes involved in identifying or decoding a given word which are reflected in several measures. One measure is phonological decoding, that represents a fundamental ability to decode the alphabetical system (Abu-Rabia, 2001; Abu-Rabia et al., 2003; Mann, 1998). Beyond phonological decoding, research demonstrates that orthographic processing plays an important role in reading (Cunningham \& Stanovich, 1990; Stanovich \& West, 1989). Orthographic knowledge is built on acquaintance with the language structure and its possible and correct forms of writing (Abu-Rabia et al., 2003; Manis, Doi, \& Bhadha, 2000; Starr \& Fleming, 2001). Reading efficacy refers to the ability for accuracy and fluency in processing words and words' components. This ability develops from year to year until it stabilizes in adulthood (Geva et al., 1997, Shany et al., 2001). Word frequency in language, reader experience and the level of regularity of its written form affect reading fluency (Calhoon \& Leslie, 2002; Gibbs \& Van-Orden, 1998; Sereno \& Rayner, 2000). Automatic information processing theories deals with reading fluency (LaBerg \& Samuels, 1974).

Recent reviews (Abu-Rabia et al., 2003; Mann, 1998; Shany et al., 2001) suggest that reading reflects a number of auxiliary cognitive processes beyond word recognition. Those include Phonological awareness which can be considered by most, crucial, cognitive process for reading development. Phonological awareness is the knowledge that spoken words are composed of phonemes and syllables, and the ability to manipulate this knowledge (Stanovich, 1986). Other studies, especially of morphologically rich languages (for example, McBride-Chang et al., 2005), demonstrate that the difficulty experienced by weak readers is reflected in morphological awareness which is connected to encoding and an understanding of the morphological transformation of words in the written and spoken language. Additionally, processes and working knowledge of syntax and semantics are also necessary for reading development. Furthermore, working memory is a process required for reading development. Working memory is related to the ability to control cognitive processing, and thus control actions executed simultaneously. Verbal working memory is the important element of verbal memory, an ability that can be measured by tasks requiring a repetition of words or word components while processing them (Shany et al., 2001). Another important cognitive process underlying reading ability is rate of phonological processing is expressed in the speed of accessing phonological information stored in long-term memory (Mann, 1998; Shany et al., 2001). Others, however, stress that reading relies heavely on visual processing. Although numerous studies demonstrate that there is no direct correlation of visual abilities and reading (Crammond, 1992; Mann, 1998), other research shows that deficits exist in the visual processing ability of weak readers, particularly in the Arabic and Hebrew languages, in which important features of the written language are presented above, beyond, and inside the written graphemes (see for example, Abu-Rabia et al., 2003; Meyler \& Breznitz, 1998).

\section{Phonological Awareness}

Phonological awareness is a conscious approach to the phonetic level of speech and the cognitive ability to use representations at this level (Ball, 1993; Mann, 1998; Stanovich, 1986; Shany et al., 2001; Wagner \& Torgesen, 1987). Phonemes are small and abstract units of sounds of the language which cannot easily be separated from each other within the spoken word, as is possible to separate syllables (Mann, 1998). Phonological awareness is one of the factors best predicting the ability of children to learn how to read (Ball, 1993; Mann, 1998; Stanovich, 1986; Wagner \& Torgesen, 1987). Additionally, the correlation between phonological awareness and reading development is extremely strong (Ball, 1993; Stanovich, 1986), although the direction of causality in this connection is not clear.

There are numerous correlative studies which demonstrate a strong link between phonological awareness and the ability to learn how to read. Children weak in phonological awareness were also found to be weak in reading (Ball, 1984; Byrne et al., 1992; Durgunoglu \& Oney, 1999; Mann, 1998; Mann \& Liberman, 1983; Shany et al., 2001; Stanovich, 1986; Wagner \& Togesen, 1987). The link between phonological awareness and ability to learn to read has been proven to be a causal one in numerous studies, in which phonological awareness in kindergarten predicts reading ability in later years (Bowey \& Francis, 1991; Bradley \& Bryant, 1983; Mann \& Liberman, 1984; Metsala, 1999; Stanovich, 1986).

Owing to the significant increase in phonological awareness of children in the $1^{\text {st }}$ grade in relation to the previous year, certain researchers contend that phonological awareness is a direct result of reading development, and that a low reading ability is the cause of weak phonological awareness (Ball, 1993; Ehri \& Wilce, 1980; Mann, 1998). In contrast, Bryant and Bradley (1985) argue that phonological awareness is a necessary but insufficient condition for reading development. Ball (1993) believes it is possible that both opinions are correct: more fundamental skills of phonological awareness (such as the identification of rhymes) are required to commence reading, while higher meta-linguistic skills (such as phoneme deletion from a word, "say rice without /r/") develop alongside reading development. Fundamental skills in phonological awareness assist in the beginning of reading development, while the reading itself deepens the phonological knowledge and skills of the reader. Mann and Stanovich (Mann, 1998; Stanovich, 1986) call this a reciprocal or mutual causationn, in which the two factors (reading and phonological awareness), influence each other. Several studies found that training for phonological awareness assists in the development of reading (Blachman, et al., 1994; Bradley \& Bryant, 1983; Brennan \& Ireson, 1997; Olfsson \& Lundbirg, 1983). The studies of Bradley and Bryant (1983, 1985) provide good testimony that phonological skills are a factor preceding reading. The children were divided into four 
groups, in which two were test groups and the two others were control groups. One test group had 40 meetings in which an exercise was conducted about the comparison of open, intermediate and closed phonemes of words while the other test group included the same arrangement, with an addition of the representation of sounds according to the alphabet. The first control group was similar to the first test group, but the comparison of words was done according to conceptual categories. The second control group was a no-intervention group. During the entire exercise, the classes continued to receive the standard reading development program. It was found that the first test group achieved more than the control groups in reading and spelling, while the second test group, which included exposure to the written word, surpassed all the other groups in reading and particularly spelling.

The sole criticism which Brennan and Ireson (1997) make of the study of Bradley and Bryant $(1983,1985)$ is that the intervention was conducted at the same time in which the children learned to read. For this reason Brennan and Ireson (1997) conducted research of kindergarten children in London, who were not learning to read. The research involved one test group and two control groups. The test group was exposed to a Danish exercise program (translated into English) containing games and meta-linguistic exercises. One control group received the American study program entitled "Success in reading and writing in kindergarten", in which unstructured exercises were conducted for phonological awareness, while the second group continued with the regular curriculum of the kindergarten. The results showed that the test group and first control group improved at the same level in reading and spelling, while the test group surpassed the other two groups in all measurements of phonological awareness. Despite the similarity in results between the test group and that of "success in reading and writing in kindergarten", certain children in the latter group did not succeed in tasks involving phonological awareness. These children were apparently required more structured and direct assistance in order to succeed in these tasks.

The study of Lyster (2002) compared the influence of training on phonological and morphological awareness in kindergarten aged children on reading development in first grade. The study had two test groups: morphological training and phonological training. In each, the children received training for thirty minutes per week over a period of 17 weeks. The two test groups demonstrated improvement in phonological skills, morphological skills and reading in comparison to the control group. However, children from less educated mothers benefited more from the meta-morphological intervention program. This pattern of results supports the theory that different meta-linguistic knowledge impacts differently the various stages of reading development (Tunmer \& Bowey, 1984). Additionally, recent study examined the influence of the linguistic distance between literary Arabic and spoken Arabic on the acquisition of fundamental processes in reading literary Arabic (Saiegh-Haddad, 2003). The assumption was that the linguistic distance (variables of the diglossia) would hinder reading development in literary Arabic. It was found that the linguistic distance between the spoken and literary language impeded the acquisition of fundamental processes of reading literary Arabic. Concerning the two variables, phonemes and the syllabic construction of words, it was found that it is more difficult for children to deconstruct phonemes in literary Arabic than phonemes in spoken Arabic, even at the end of first grade. It was further seen that syllables hinder the phonemic deconstruction when the phonemes were from the literary language and located as a prevocal prefix. Additionally, it was discovered that the linguistic distance between the two versions of the language hampers reading development in first grade. Thus, the syllabic literary construction hindered reading development more than the literary phonological structure. In contrast, phonemes and syllables from the spoken language were excellently encoded.

The results of Saiegh-Haddad's (2003) research demonstrate that in order to assist children in reading development in first grade, the educational system may need to expose the children to the literary language before they enter the first grade. This is further supported by the findings of Abu-Rabia, which show that exposure to the literary language prior to first grade assists children beginning to read and in reading comprehension (AbuRabia, 2002).

\section{The Current Research}

The current research examined the influence of training kindergarten children in phonological skills, separately, on their subsequent reading performance in first grade. The results of these intervention program were compared to a no-intervention control group. Although the training was conducted in vocabulary elements of literary Arabic an effort was made to use as many items as possible which are similar to spoken Arabic. The question was, would phonological training in the literary language enhance phonological awareness? And would phonological training in kindergarten assist and advance literary Arabic reading development in first grade?

The working hypotheses was that there would be a clear influence of the phonological training program on the respective skills, such that children trained in phonological skills will attain higher scores on tests of phonological awareness than the control group, Also, it was expected that the training program would enhance reading ability in first grade.

\section{Method}

\section{Participants}

57 kindergarten children from a private school in Haifa participated in this research. 30 of them participated in the phonological intervention program, and 27 children had no intervention program and constituted the control group. Children in this kindergarten do not learn to read or write. One of the children left the phonological group and two left the control group. The total number of the participants included in the statistical analysis was 29 (14 males and 15 females) from the phonological group, 25 from the control group (12 males and 13 females).

\section{Subjects and Design}

The training session for trainers included a presentation of background information on linguistic and meta-linguistic issues, reading development and the correlation between these variables. Additionally, the trainers learned to conduct each of the intervention programs for each group. The trainers entered the intervention classes simultaneously and conducted the program for each class in groups, each group containing 10 children on average. The trainers further underwent training in conducting the pre and post-intervention tests. The reading tests in first grade were administered by the trainer. 
The intervention was conducted in the literary Arabic language. The training lasted for 8 weeks, and during each week each group received three sessions of 30 - 45 minutes each.

The phonological training group: This group received training in phonological awareness. The training included the use of rhymes, blending, segmenting and general sound recognition. During the training, the children were exposed to letters and letter combinations which represent the sounds and consonants with which they are dealing. This intervention mode was based on the methods of Lyster (2002) (adapted to Arabic from English). Exposure to print occurred during language games which were built for the purposes of this research. Actually children saw the word/words included in the training set. For example, during a game of word identification with a rhyme or sound opening differently, they saw a group of target words on cardboard. Despite the exposure to the written word, direct instruction of grapheme-phoneme correspondence was not conducted.

Control group: this group received no intervention whatsoever. The research assistants' visits to this group were only during the pre and post tests.

\section{Procedure}

The pre-tests were administered in kindergarten to the experimental group from the beginning of the second trimester of the school year. The intervention program commenced at the beginning of the final trimester of the school year. The posttests were administered at the conclusion of the intervention programs. Reading tests were given to both groups at the beginning of the second trimester of the school year in first grade. Each of the tests were administered to both groups at almost the same time.

\section{Measures}

For purposes of this study, a set of tests to examine the effect of the interventions programs (pre and posttests) was constructed, as well as a set of reading tests for first grade in Arabic.

\section{Pre and Post Measures}

Phonological awareness tests:

1) Rhyme Match Test: In this test a word is presented, and after that three other words (nouns or verbs) are presented. The child is required to choose one of these words to rhyme with the first presented word. All the words given in this test are presented orally and with a line drawing or colored illustration. The test include 14 items $(\alpha=.815)$.

2) Syllables Count: The child heard 11 words, and was asked to count its' syllables. For each syllable the child was asked to knock on the table or clap hands. Two examples were given prior to the test $(\alpha=.907)$.

3) Phonemes Count: This test was constructed in a manner similar to the previous one. The child heard 15 items in ascending order according to their level of difficulty. For each item, the child was asked to count the phonemes. While counting each phoneme, he/she was asked also to clap his/her hands or knock on the desk. Three examples were given prior to the actual test $(\alpha=0.767)$.

4) First phoneme match: The test included 12 items presented in ascending order, according to word size and linguistic distance from the spoken language. The child heard each item, after which he was asked to note which of three choice words shared a first phoneme with the target item. All of the items were similar to the target item in regards of word size and complexity. Pictures illustrating the items were shown to the children $(\alpha=.766)$.

5) Last phoneme match: A similar task to the previous one, in which the child was asked to match the target word with one of three words according to its last phoneme $(\alpha=.875)$. The task included 14 items.

General abilities and phonological processing tests:

1) Peabody Picture Vocabulary Test-Revised: A test examining vocabulary in which the child is told words and he must mark one out of four pictures. This test has no norms in Israel. The 50 first items of the test, translated into literary Arabic from the English version of the test (Dunn \& Dunn, 1981) were used on this research.

2) Verbal memory tests: Based on the Hebrew test of Shatil (2002) the test comprises 20 items. The child was requested to repeat meaningless syllabic constructions which vary from one to five syllables in length.

3) Raven Standard Progressive Matrices (children's version): The test includes matrices with problems becoming progressively more difficult. The test is intended to examine a person's "inductive" ability (Zaaiman, Van der Filer, \& Thijs, 2001). The children's version includes three sets of 12 colorful items.

\section{Reading Tests:}

A set of tests were constructed to examine reading ability. Performance was tested by scoring reading accuracy and speed. Note that the Alpha Cronbach was computed from the test results of the current study.

1) Words recognition test: The test included a column of pictures and across from it a column of words. The child was required to match the picture with the corresponding word. The test included 20 items $(\alpha=.646)$. The test was administered in a group manner, to each class separately.

2) Syllable reading: the child was asked to read 20 syllables presented on a single test page $(\alpha=.818)$ syllables were of max 3 consonants.

3) Pseudo words reading: Included a list of 20 pseudo words $(\alpha=.835)$. words in this test was one or two syllables. The syllables were part of the words children usually learn in $1^{\text {st }}$ grade.

4) Word reading: Words were chosen so that part of them would be morphologically simple, including one syllable, like the word " $y "$ " (/la/ which means "No"). the other words were gradually more comlex, like the word " "مَرَكَتْ "/tarakat/, which means "she left"). Words were organized by frequency, as advised by the two teachers checking the tests. This task included 42 words in which the child was required to read them all ( $\alpha$ $=.887$ ).

\section{Results}

The results of the pre intervention, post-intervention interval (kindergarten), and the one year after ( $1^{\text {st }}$ grade), were used to assess whether the intervention program designed to enhance phonological awareness actually would enhance phonological awareness abilities. The results of the reading tests administered about one year after the intervention in order to assess whether the intervention programs could improve reading abilities in comparison to the control, no-intervention group. The reading measures of both groups were also compared in terms of gender differences. Finally, the correlations between performance in the 
different tests in Kindergarten and the reading test scores in the first grade, and between the different reading tests administered in $1^{\text {st }}$ grade are reported.

\section{Kindergarten}

A new measure of "combined phonological score" was derived by simply adding the "first phoneme match" score to the "last phoneme score". The reason lying behind this measure was that these two tests rely on about the same factor (phonological awareness) and both of them were tested in exactly the same manner.

A MANOVA was used to test the initial differences between the study groups (phonological intervention group and control (no-intervention) group, in pretest measures. The MANOVA results showed that the initial performance on the verbal memory test $\left(F_{(1,52)}=3.14, p<.05\right)$ was significantly different for both groups. A post hoc test (Scheffe) showed a marginally significant difference between the Phonological and the control groups $(p=.051)$, with the Phonological group performing better. Finally, the initial performance of the both groups in the phoneme count test was also significantly different $\left(F_{(1,52)}=4.15, p<.05\right)$. A post hoc test (Scheffe) showed a significant difference between the Phonological and the control groups $(p=.02)$, with better performance in the control group.

A second MANOVA was run to test the differences in performance in both study groups, after the intervention interval, in the post tests. Post hoc tests (Scheffe) showed a significant difference in the performance of the both study groups in the phoneme count and verbal memory tests, tests in which differences between the groups were found even before the intervention period (i.e., in the pre-tests). However, after the intervention interval, the combined phonology group showed a significant difference from the control group. The Phonological group also showed a marginally significant improvement in comparison to the control group.

In order to test the possible differential effects of the intervention programs, we compared the performance of the participants of both study groups in the two kindergarten sessions (pre and post tests) for each of the tests, separately, using repeated measures ANOVAs. The results showed that both groups improved in the general ability tests, specifically in the Peabody, Raven and Verbal memory tests. In some tests only the phonological intervention group, but not the control group, showed significant improvements across the intervention period. These tests included the last phoneme match test (although the latter test showed only marginally significant improvement in the Phonological group). Only the Phonological group improved in the phoneme count test. The control group showed significant improvement only in naming time. However, an analysis of the number of errors made, by the control group, showed that there was a trade off between accuracy and fluency, since these participants had also increased the number of errors made in the post test.

\section{1) Peabody}

Both study groups (Phonological, and control) showed a significant improvement in the Peabody test. Comparisons using a 2 groups (Phonological and control; as between-subject factor) $\times 2$ time points (pre and post tests; as within-subject factor) ANOVA, showed a main effect for time-point $\left(F_{(1,52)}=26.43, p\right.$ $<.001$ ) with no significant interaction (groups $\mathrm{x}$ time-points). A paired-samples t-test conducted for each group separately, showed significant improvement in both groups: Phonological, and control $\left(t_{(25)}=-3.6, p=.001 ; t_{(23)}=-3.38, p<.01\right.$, respectively).

\section{2) Raven}

Both study groups tested in the Raven test showed a significant improvement. Comparisons using a 2 group (Phonological and control, as between-subject factor) $\times 2$ time point (pre and post tests; as within-subject factor) ANOVA showed a main effect for time-point $\left(F_{(1,52)}=33.52, p<.001\right)$, but no significant interaction (groups $x$ time-points) $\left(F_{(2,52)}=0.81, p=0.51\right)$. A paired-samples t-test conducted for each group separately, showed significant improvements in both study groups: phonological and control groups $\left(t_{(25)}=-2.77, p<.05 ; t_{(23)}=-4.74, p\right.$ $<.001$, respectively).

3) Verbal Memory

Both study groups tested in the Verbal Memory test showed a significant improvement. Comparisons using a 2 groups (Phonological and control, as between-subject factor) $\times 2$ time points (pre and post tests; as within-subject factor) ANOVA showed a main effect for time-point $\left(F_{(1,52)}=26.31, p<.001\right)$ with no significant interaction (groups $\times$ time-points). There was significant main effect of group (between-subjects; $\left[F_{(1,52)}\right.$ $=6.92, p<.001])$. A paired-samples t-test conducted for each group separately, showed significant improvements in Phonological group $\left(\mathrm{t}_{(26)}=-2.83, p<.01\right)$. The control group showed only a marginally significant improvement $\left(\mathrm{t}_{(23)}=-1.98, p\right.$ $=.059$ ).

4) Combined Phoneme Match Score (First and Last Phoneme Match)

As the first and last phoneme match attempt to test the same ability (phonological awareness) at the same manner, a combined measure was computed for both of the tests.

In both study groups tested in the combined phoneme match score there was no significant improvement. Comparisons using a 2 group (Phonological and control, as between-subject factor) $\times 2$ time point (pre and post tests; as within-subject factor) ANOVA showed a main effect for time-point $\left(F_{(1,52)}=\right.$ $12.67, p=.001)$ with a significant interaction (groups $\times$ timepoints) $\left(F_{(2,52)}=5.34, p<.01\right)$. There was significant main effect of group (between-subjects; $\left.\left[\mathrm{F}_{(2,74)}=4.41, p<.05\right]\right)$. Post hoc test (Scheffe) demonstrated that the participants of the Phonological group showing better performance than the control group $(p<.05)$.

\section{Reading Tests in $\mathbf{1}^{\text {st }}$ Grade}

To test for differences between both study groups in reading abilities ANOVA tests were run for each of the reading tests separately. As opposed to assumptions, there were no significant differences between the study groups in the performance of any of the tests that were administered to measure reading abilities.

\section{Correlation Analyses}

In order to study the relationship between the performance in the pre-test battery and the participants' reading abilities, the correlations between performance measures in the various tests in the pre-test and the reading test measures were computed. Table 1 shows the Pearson's correlations between pre tests measured in kindergarten and the reading tests measured in $1^{\text {st }}$ grade. As can be seen, none of the pre tests correlated significantly with word recognition test. We exclude the verbal mem- 


\section{R. IBRAHIM}

Table 1.

Pearson correlations between pre tests and post tests admitted in kindergarten and reading tests admitted in the $1^{\text {st }}$ grade.

\begin{tabular}{|c|c|c|c|c|c|c|c|c|c|}
\hline & $\begin{array}{c}\text { Word } \\
\text { recognition }\end{array}$ & $\begin{array}{l}\text { Syllable } \\
\text { reading }\end{array}$ & $\begin{array}{l}\text { Pseudo word } \\
\text { reading }\end{array}$ & $\begin{array}{l}\text { Word } \\
\text { reading }\end{array}$ & & $\begin{array}{c}\text { Word } \\
\text { recognition }\end{array}$ & $\begin{array}{l}\text { Syllable } \\
\text { reading }\end{array}$ & $\begin{array}{l}\text { Pseudo word } \\
\text { reading }\end{array}$ & $\begin{array}{l}\text { Word } \\
\text { reading }\end{array}$ \\
\hline pre verbal memory & $.230\left(^{*}\right)$ & .166 & $.266\left(^{*}\right)$ & $.268\left(^{*}\right)$ & post verbal memory & .091 & $.310\left(^{* *}\right)$ & $.321\left(^{* *}\right)$ & $.308\left(^{* *}\right)$ \\
\hline pre Peabody & -.051 & .179 & .176 & .183 & post Peabody & .16 & .189 & .177 & .17 \\
\hline pre raven & -.21 & $.261\left(^{*}\right)$ & .196 & .147 & post raven & -.044 & $.269\left(^{*}\right)$ & $.278\left(^{*}\right)$ & .173 \\
\hline pre rhyme match & .055 & $.220\left(^{*}\right)$ & .217 & $.232\left(^{*}\right)$ & post rhyme match & $.275\left(^{*}\right)$ & $.224\left(^{*}\right)$ & $.295\left(^{* *}\right)$ & $.249\left(^{*}\right)$ \\
\hline pre syllable count & .026 & .087 & .079 & .04 & post syllable count & .134 & $.246\left(^{*}\right)$ & $.242\left(^{*}\right)$ & .145 \\
\hline pre phoneme count & .204 & -.065 & .018 & -.076 & post phoneme count & .083 & .095 & .148 & .111 \\
\hline pre first phoneme match & .075 & $.273\left(^{*}\right)$ & $.344\left(^{* *}\right)$ & $.321\left(^{* *}\right)$ & post first phoneme match & $.372\left(^{* *}\right)$ & $.360\left(^{* *}\right)$ & $.455\left(^{* *}\right)$ & $.390\left(^{* *}\right)$ \\
\hline pre last phoneme match & .048 & .195 & .149 & .15 & post last phoneme match & $.318\left(^{* *}\right)$ & $.419\left(^{* *}\right)$ & $.395\left(^{* *}\right)$ & $.308\left(^{* *}\right)$ \\
\hline
\end{tabular}

Note: ${ }^{* *}$ Correlation is significant at the .01 level (2-tailed); ${ }^{*}$ Correlation is significant at the 0.05 level (2-tailed).

ory test that correlated with this test in a low significance and correlation $(\mathrm{r}=0.230, p<.05)$.

A similar correlation analysis was performed to study the relationship between the performance in the post-test that took place in kindergarten, and the reading tests admitted in the $1^{\text {st }}$ grade (see Table 1). The performance levels in the tests rhyme match, first phoneme match, last phoneme match were significantly correlated with all of the reading tests. The correlations in those tests varied from $0.224-0.455$ (absolute value), all in high significance. Most of the other post tests correlated with part of reading tests too.

The Pearson correlations between the different reading tests showed that all the reading tests correlated with each other with a high level of significance, except for the word recognition test. This suggests that word recognition test might examine things that are beyond merely reading abilities. It could, for example, test visual perception ability, or anything regarding the visualspatial abilities.

\section{Discussion}

The effect of phonological intervention program in kindergarten on the development of reading abilities in native Arab speaking children was examined and discussed. The main question was, whether a phonological awareness training program can improve phonological awareness abilities; and whether this training program may help to improve reading abilities in the first grade in comparison to a no-intervention control group.

The results showed that the phonological intervention group was improved in a number of phonological tasks including the last phoneme match task and the phoneme count. However, the only task, in which the children of the no intervention control group showed improvement between the initial and the second testing sessions, was the naming task, This improvement in speed, therefore, can be ascribed to a speed accuracy trade-off.

The results of the reading and spelling tests administered to the participants of both groups in the first grade showed that the intervention groups had at least some advantage over the control group in measures of fluency in the syllable reading, pseudo word reading and word reading. But, those differences were not statistically significant.

The effect of phonological intervention program on phonological awareness, is in line with previous results (for example, Ball \& Blachman, 1988; Blachman et al., 1994; Olfsson \&
Lundberg, 1983; Brennan \& Ireson, 1997; Gustafson, Ferreira, \& Ronnberg, 2007). Thus, awareness of word structure at the level of phoneme is related to reading acquisition. Lyster (2002) found these arguments supported also by the results of her study, in which the phonological group developed their linguistic an morphological knowledge to a significantly higher level than children in the control group. Casalis \& Louis-Al-exandre (2000) went beyond these results and found in a non-intervention longitudinal study that phonological awareness explained a major part of the variance in reading measures in the first grade. Furthermore, the phonological score explained a significant part of the variance of both decoding and reading comprehension scores in second grade.

In a recent study conducted by McBride-Chang et al., (2005), they developed this idea by investigating how phonological awareness is associated with word recognition in different scripts among second graders. They critically address the emphasis put on the importance of phonological awareness for early reading in current textbooks of reading development. McBride-Chang et al., (2005) suggest that the extent to which phonological awareness is associated with reading development likely depends on the language in which it occurs and the script to which it is linked as well as the developmental level of the child. McBride-Chang et al., (2005) provide evidence in support of the notion that phonological awareness may be more important for reading in English and Korean than for reading in Chinese.

In the current study, the phonological group was improved in the phoneme count test. This pattern of results was also found by Lyster (2002) implying that only explicit teaching (of how to segment phonemes) may enhance the children's ability to segment phonemes in a given word. However, the Phonological group did not show a significant improvement across the intervention period in the rhyme match or the syllable count. Also, the current results in reading showed that, there were no significant differences between groups in the performance of the reading tests in the $1^{\text {st }}$ grade. This finding is surprising comparing to English reading population since previous studies found that phonological intervention programs in kindergarten do enhance reading abilities in $1^{\text {st }}$ graders (for example, Brennan \& Ireson, 1997; Ball \& Blachman, 1988; Blachman et al., 1994). The results of this study, in addition to results of the previous studies suggest that there is a difficulty in processing Arabic language by native Arabic readers and this is apparently 
due to three factors related to language characteristics. The first factor might be relatad to the effects of diglossia (the fact that children learn to read a language in which they are not fluent) (see Ibrahim \&Aharon-Perez, 2005; Abu-Rabia, 1997; SaieghHaddad, 2003). The second factor might be relatad to the fact that Arabic orthography is less transparent/shallow and the unique relationship between graphemes and phonemes in Arabic (Assad \& Eviatar, 2010). According to the "orthographic depth hypothesis", decoding of deeper orthographies is less reliant on phonology. The third factor might be relatad to the visual characteristics of Arabic orthography, and it's orthographic complexity that result in a specific reading strategy among skilled readers that involves the cerebral hemispheres differently in Arabic than in Hebrew or English (Ibrahim, Eviatar, \& AharonPeretz, 2002; Eviatar, Ibrahim, \& Ganayim, 2004; Eviatar \& Ibrahim, 2007; Ibrahim \& Eviatar, 2009; Taha, Ibrahim, \& Khateb, 2012).

\section{Conclusion}

The whole findings of the current research do not allow us to ignore the fact that normal Arab child (and for a further extent child with learning disability), who encounters special difficulties in reading acquisition need special pedagogical methods and systematical professional intervention to overcome these difficulties that the Arabic language imposes. On that regard, Arab teachers who deal every day with the ability of students to learn their native language, must monitor the reading learning process, and to intervene to shape it toward effectiveness.

\section{REFERENCES}

Abu-Rabia, S. (1997a). Reading in Arabic orthography: The effect of vowels and context on reading accuracy of poor and skilled native Arabic readers in reading paragraphs, sentences, and isolated words. Journal of Psycholinguistic Research, 26, 465-482. doi:10.1023/A:1025034220924

Abu-Rabia, S. (1997b). Reading in Arabic orthography: The effect of vowels and context on reading accuracy of poor and skilled native Arabic readers. Reading and Writing: An Interdisciplinary Journal, 9, 65-78. doi:10.1023/A:1007962408827

Abu-Rabia, S. (1997c). The need for cross-cultural considerations in reading theory: The effects of Arabic sentence context in skilled and poor readers. Journal of Research in Reading, 20, 137-147. doi:10.1111/1467-9817.00026

Abu-Rabia, S. (2001). The role of vowels in reading Semitic scripts data from Arabic and Hebrew. Reading and Writing: An Interdisciplinary Journal, 14, 39-59. doi:10.1023/A:1008147606320

Abu-Rabia, S. (2002). Reading in a root-based-morphology language: The case of Arabic. Journal of Research in Reading, 25, 299-309. doi:10.1111/1467-9817.00177

Abu-Rabia, S., Share, D., \& Mansour, M. S. (2003). Word recognition and basic cognitive processes among reading disabled and normal readers in Arabic. Reading and Writing: An Interdisciplinary Journal, 16, 423-442. doi:10.1023/A:1024237415143

Ball, E. W. (1993). Phonological awareness: What's important and to whom? Reading and Writing: An Interdisciplinary Journal, 5, 141159. doi:10.1007/BF01027481

Ball, E. W., \& Blachman, B. A. (1988). Phoneme segmentation training: Effect on reading readiness. Annals of Dyslexia, 38, 208-225. doi:10.1007/BF02648257

Bertelson, P., Morais, J., Alegria, J., \& Content, A. (1985). Phonetic analysis capacity and learning to read. Nature, 313, 73-74. doi: $10.1038 / 313073 \mathrm{c} 0$

Blachman, B. A., Ball, E., Black, R. S., \& Tangel, D. M. (1994). Kindergarten teachers develop phoneme awareness in low-income, in- ner-city classrooms: Does it make a difference? Reading and Writing: An Interdisciplinary Journal, 6, 1-18. doi:10.1007/BF01027275

Bowey, J. A., \& Francis, J. (1991). Phonological analysis as a function of age and exposure to reading instruction. Applied Psycholinguistics, 12, 91-121. doi:10.1017/S0142716400009395

Bradley, L., \& Bryant, P. E. (1983). Categorizing sounds and learning to read-A causal connection. Nature, 301, 419-421. doi: $10.1038 / 301419 \mathrm{a} 0$

Brennan, F., \& Ireson, J. (1997). Training phonological awareness: A study to evaluate the effects of a program of metalinguistic games in kindergarten. Reading and Writing: An Interdisciplinary Journal, 9, 241-263. doi:10.1023/A:1007979321948

Breznitz, Z. (2002). Asynchrony of visual-orthographic and auditoryphonological word recognition processes: An underlying factor in dyslexia. Reading and Writing, 15, 15-42. doi:10.1023/A:1013864203452

Bryant, P., \& Bradley, L. (1985). Children's reading problems. Oxford: Blackwell.

Byrne, B., Freebody, P., \& Gates, A. (1992). Longitudinal data on the relations of word-reading strategies to comprehension, reading time, and phonemic awareness. Reading Research Quarterly, 27, 140-151. doi: $10.2307 / 747683$

Calhoon, J. A., \& Leslie, L. (2002). A longitudinal study of the effects of word frequency and rime neighborhood size on beginning readers' rime reading accuracy in words and nonwords. Journal of Literacy Research, 34, 39-58. doi:10.1207/s15548430jlr3401_2

Carlisle, J. (1995). Morphological awareness and early reading achievement. In L. B. Feldman (Ed.), Morphological aspects of language processing (pp. 189-209). Hillsdale: Lawrence Erlbaum Associates.

Cossu, G., Shankweiler, D., Liberman, I. Y., Katz, L., \& Tola, G. (1988). Awareness of phonological segments and reading ability in Italian children. Applied Psycolinguistics, 9, 1-16. doi:10.1017/S0142716400000424

Crammond, J. (1992). Analyzing the basic developmental processes of children with specific types of learning disability. In R. Case (Ed.), The mind's staircase (pp. 285-302). Hillsdale: Lawrence Erlbaum Associates.

Cunningham, A. E., \& Stanovich, K. E. (1990). Assessing print exposure and orthographic processing skill in children: A quick measure of print experience. Journal of Educational Psychology, 82, 733-740. doi:10.1037/0022-0663.82.4.733

Da Fontoura, H. A., \& Siegel, L. S. (1995). Reading, syntactic and working memory skills of bilingual Portuguese-English Canadian children. Reading and Writing: An Interdisciplinary Journal, 7, 139-153. doi:10.1007/BF01026951

Dash, U. N., \& Mishra, H. C. (1992). Bilingualism and metalinguistic development: Evidence from kond tribal culture. Psychological Studies, 37, 81-87.

de Manrique, A. M. B., \& Gramigna, S. (1984). La segmentación fonológica y silábica en ni nos de preescolar y primer grado. Lectura y Vida, 5, 4-14.

Doyle, A., Champagne, M., \& Segalowitz, N. (1978). Some issues on the assessment of linguistic consequences of early bilingualism. In M. Paradis (Ed.), Aspects of bilingualism (pp. 13-20). Colombia: Hornbeam Press.

Dunn, L. M., \& Dunn, L. M. (1981). Peabody picture vocabulary testrevised. Circle Pines, MN: American Guidance Service, Inc.

Durgnoglu, A. Y., \& Oney, B. (1999). A cross linguistic comparison of phonological awareness and word recognition. Reading and Writing: An Interdisciplinary Journal, 11, 281-299. doi:10.1023/A:1008093232622

Edwards, D., \& Christophersen, H. (1988). Bilingualism, literacy and meta linguistic awareness in preschool children. British Journal of Developmental Psychology, 6, 235-244. doi:10.1111/j.2044-835X.1988.tb01097.x

Ehri, L., \& Wilce, L. (1980). The influence of orthography on readers' conceptualization of the phonemic structure of words. Applied Psycholinguistics, 1, 371-385. doi:10.1017/S0142716400009802

Eviatar, Z., \& Ibrahim, R. (2001). Bilingual is as bilingual does: Metalinguistic abilities of Arabic-speaking children. Applied Psycholin- 


\section{R. IBRAHIM}

guistics, 21, 451-471. doi:10.1017/S0142716400004021

Eviatar, Z., Ibrahim, R., \& Ganayim, D. (2004). Orthography and the hemispheres: Visual and linguistic aspects of letter processing. Neuropsychology, 18, 174-184. doi:10.1037/0894-4105.18.1.174

Geva, E., Wade-Wooley, L., \& Shany, M. (1997). Development of reading efficiency in first and second language. Scientific Studies of Reading, 1, 119-144. doi:10.1207/s1532799xssr0102 2

Gibbs, P., \& van Orden, G. C. (1998). Pathway selection's utility for control of word recognition. Journal of Experimental Psychology: Human Perception and Performance, 24, 1162-1187. doi:10.1037/0096-1523.24.4.1162

Gustafson, S., Ferreira, J., \& Rönnberg, J. (2007). Phonological or orthographic training for children with phonological or orthographic decoding deficits. Dyslexia, 13, 211-229. doi:10.1002/dys.339

Ibrahim, R. (2009). The cognitive basis of diglossia in Arabic: Evidence from a repetition priming study within and between languages. Psychology Research and Behavior Management, 12, 95-105.

Ibrahim, R., \& Aharon-Peretz, J. (2005). Is literary Arabic a second language for native Arabic speakers? Evidence from semantic priming study. Journal of Psycholinguistic Research, 34, 51-70. doi:10.1007/s10936-005-3631-8

Ibrahim, R., Eviatar, Z., \& Aharon-Peretz, J. (2002). The characteristics of Arabic orthography slow its processing. Neuropsychology, 16, 322326. doi:10.1037/0894-4105.16.3.322

Ibrahim, R., Eviatar. Z., \& Aharon-Peretz, J. (2007). Metalinguistic awareness and reading performance: A cross language comparison. The Journal of Psycholinguistic Research, 36, 297-317. doi:10.1007/s10936-006-9046-3

Ibrahim, R., \& Eviatar, Z. (2009). Language status and hemispheric involvement in reading: Evidence from trilingual Arabic speakers tested in Arabic, Hebrew, and English. Neuropsychology, 23, 240254. doi:10.1037/a0014193

LaBerge, D., \& Samuels, J. (1974). Toward a theory of automatic information processing in reading. Cognitive Psychology, 6, 293-323. doi:10.1016/0010-0285(74)90015-2

Lyster, S. A. H. (2002). The effects of morphological vs phonological awareness training in kindergarten on reading development. Reading and Writing: An Interdisciplinary Journal, 15, 261-294. doi:10.1023/A:1015272516220

Manis, F. R., Doi, L. S., \& Bhadha, B. (2000). Naming speed, phonological awareness, and orthographic knowledge in second graders. Journal of Learning Disabilities, 33, 325-333. doi:10.1177/002221940003300405

Mann, V. (1998). Language problems: A key to early reading problems. In B. Wong, Learning about learning disabilities (pp. 163-193). San Diego: Academic Press.

Mann, V. A., \& Liberman, I. Y. (1984). Phonological awareness and verbal short-term memory. Journal of Learning Disabilities, 17, 592599. doi:10.1177/002221948401701005

McBride-Chang, C., Cho, J.-R., Liu, H., Wagner, R. K., Shu, H., Zhou, A., Cheuk, C., \& Muse, A. (2005). Changing models across cultures: Associations of phonological awareness and morphological structure awareness with vocabulary and word recognition in second graders from Beijing, Hong Kong, Korea, and the United States. Journal of Experimental Child Psychology, 92, 140-160. doi:10.1016/j.jecp.2005.03.009

Metsala, J. L. (1999). The development of phonemic awareness in reading disabled children. Applied Psycholinguistics, 20, 149-158. doi:10.1017/S0142716499001058

Meyler, A., \& Breznitz, Z. (1998). Developmental associations between verbal and visual short-term memory and the acquisition of decoding skill. Reading and Writing: An Interdisciplinary Journal, 10, 519540. doi:10.1023/A:1007915517339

Olfson, A., \& Lundberg, I. (1983). Can phonemic awareness be trained in kindergarten? Scandinavian Journal of Psychology, 24, 35-44. doi:10.1111/j.1467-9450.1983.tb00473.x

Rayner, K., \& Pollatsek, A. (1989). Psychology of reading. Englewood Cliffs, NJ: Prentice Hall.

Saiegh-Haddad, E. (2003). Linguistic distance and initial reading acquisition: The case of Arabic diglossia. Applied Psycholinguistics, 24, 431-451. doi: 10.1017/S0142716403000225

Sereno, S. C., \& Rayner, K. (2000). Spelling sound regularity effects on eye fixation in reading. Perception and Psychophysics, 62, 402-409. doi:10.3758/BF03205559

Shani, M., Zeiger, T., \& Ravid, D. (2001). Development of assessment tool for basic processes in reading and writing. Script, 2, 167-203.

Shatil, E. (2002). Shatil's battery. Qiryat Bialik: Ach Publishers, Ltd.

Stanovich, K. E. (1986). Matthew effects in reading: Some consequences of individual differences in the acquisition of literacy. Reading Research Quarterly, 21, 360-406. doi:10.1598/RRQ.21.4.1

Stanovich, K. E., \& West, R. (1989). Exposure to print and orthographic processing. Reading and Research quarterly, 24, 402-429. doi: $10.2307 / 747605$

Starr, M. S., \& Fleming, K. K. (2001). A rose by any other name is not the same: The role of orthographic knowledge in homophone confusion errors. Journal of Experimental Psychology: Learning, Memory and Cognition, 27, 744-760. doi:10.1037/0278-7393.27.3.744

Taha, H., Ibrahim, R., \& Khateb, A. (2012). How does Arabic orthographic connectivity modulate brain activity during visual word recognition: An ERP study. Brain Topography, 26, 292-302.

Tunmer, W. E., \& Bowey, J. (1984). Metalinguistic awareness and reading acquisition. In W. E. Tunmer, C. Pratt, \& M. L. Herriman (Eds.), Metalinguistic awareness in children: Theory, research and implications (pp. 144-168). Berlin: Springer-Verlag. doi:10.1007/978-3-642-69113-3

Wagner, R. K., \& Torgesen, J. K. (1987). The nature of phonological processing and its causal role in the acquisition of reading skills. Psychological Bulletin, 101, 192-212.

doi:10.1037/0033-2909.101.2.192

Zaaiman, H., van der Filer, H., \& Thijs, G. D. (2001). Dynamic testing in selection for an educational programme: Assessing south African performance on the raven progressive matrices. International Journal of Selection and Assessment, 9, 258-269. doi:10.1111/1468-2389.00178 